\title{
The Margins' Challenge: Risk Factors of Residual Disease After Breast Conserving Surgery in Early-stage Breast Cancer
}

\author{
PIERO FREGATTI ${ }^{1,2}$, MARCO GIPPONI $^{2}$, GIULIA ATZORI ${ }^{1}$, RAFFAELE DE ROSA ${ }^{1}$, \\ RAQUEL DIAZ ${ }^{1}$, CHIARA CORNACCHIA ${ }^{1}$, MARCO SPARAVIGNA ${ }^{1}$, ALESSANDRO GARLASCHI ${ }^{3}$, \\ LILIANA BELGIOIA ${ }^{4,5}$, ALESSANDRA FOZZA ${ }^{4}$, FRANCESCA PITTO ${ }^{6}$, LUCA BONI $^{7}$, \\ EVA BLONDEAUX ${ }^{7}$, FRANCESCA DEPAOLI $^{2}$, FEDERICA MURELLI $^{1,2}$, SIMONETTA FRANCHELLI $^{2}$, \\ GABRIELE ZOPPOLI ${ }^{8,9}$, MATTEO LAMBERTINI $^{8,9,10}$ and DANIELE FRIEDMAN ${ }^{1,2}$ \\ ${ }^{1}$ Department of Surgical Sciences and Integrated Diagnostic (DISC), \\ School of Medicine, University of Genoa, Genoa, Italy; \\ ${ }^{2}$ Breast Surgery Clinic, San Martino Policlinic Hospital, Genoa, Italy; \\ ${ }^{3}$ Diagnostic Senology, San Martino Policlinic Hospital, Genoa, Italy; \\ ${ }^{4}$ Radiation Oncology Department, San Martino Policlinic Hospital, Genoa, Italy; \\ ${ }^{5}$ Radiation Oncology Department, San Martino Policlinic Hospital, \\ School of Medicine, University of Genoa (DISSAL), Genoa, Italy; \\ ${ }^{6}$ Pathology Unit, San Martino Policlinic Hospital, Genoa, Italy; \\ ${ }^{7}$ Clinical Epidemiology Unit, San Martino Policlinic Hospital, Genoa, Italy; \\ ${ }^{8}$ Internal Medicine and Oncology Unit, San Martino Policlinic Hospital, Genoa, Italy; \\ ${ }^{9}$ Department of Internal Medicine and Medical Specialties (DIMI), \\ School of Medicine, University of Genoa, Genoa, Italy; \\ ${ }^{10}$ Department of Medical Oncology, U.O.C Medical Oncology Clinic, \\ San Martino Policlinic Hospital, Genoa, Italy
}

\begin{abstract}
Background/Aim: Clinicopathological features of patients undergoing margin enlargement after lumpectomy for early breast cancer with positive/close excision margins were analyzed in order to define whether a re-operative procedure could have been avoided. Furthermore, a standardized protocol of specimen orientation was adopted in order to optimize both the widening procedure as well as the oncologic outcome. Patients and Methods: A retrospective analysis was performed including pre-, peri-, and post-operative parameters, and a predictive score by means of a multivariate model was developed using all clinically and statistically significant variables associated with residual disease $(R D)$. Results: RD was significantly related to positive tumor margins, hormone receptor negative, HER2-positive, and
\end{abstract}

This article is freely accessible online.

Correspondence to: Marco Gipponi, MD, Breast Surgery Clinic Ospedale Policlinico San Martino, L.go R. Benzi, 10, 16132 Genoa, Italy. Tel: +39 0105558805, e-mail: marco.gipponi@hsanmartino.it

Key Words: Breast cancer surgery, excision margin, intraoperative pathologic examination. tumors with high Ki67 proliferation index $(p<0.001)$; the corresponding contribution to the prognostic score was as follows: close margins, 3 points; hormone receptor positive disease, 2 points; low Ki67, 2 points; HER2 negativity, 1 point. In 102 patients with a score $>3$, only 2 patients (2.0\%) had RD, while in 81 patients with a score $\leq 3,55$ patients $(67.9 \%)$ had RD $(p<0.001)$. Conclusion: This predictive model might aid in clinical-decision making of patients with positive margins who actually require a widening procedure after intraoperative and/or definitive histology.

Breast conserving surgery (BCS) is defined as the resection of breast tumor surrounded by a portion of normal tissue; it represents the worldwide treatment for early-stage breast cancer (Stage I-II or Stage III in selected cases) with longterm survival similar to mastectomy (1). From the operative standpoint, non-palpable lesions usually undergo preoperative localization by means of clip positioning, charcoal, or radioactive seeds peri-tumoral injection; following excision, the tumor bed is marked with four clips placed at the corner points in order to be easily identified for radiation therapy planning. Hence, the breast sample is sent for intraoperative macroscopic assessment, and the margins of excision are inked in order to define the minimal 
distance between the inked margins and tumor cells (2-4). Clear margins of excision are mandatory in BCS in order to avoid recurrence due to residual tumor cells (ipsilateral breast tumor recurrence, IBTR) and, according to recent guidelines, the standard for invasive breast cancer should be "no ink on tumor" (5-7). Conversely, in patients with a diagnosis of ductal carcinoma in situ (DCIS) a $2 \mathrm{~mm}$ clearance from the margins of excision is recommended to minimize IBTR; larger resections do guarantee no added benefit (8-10).

Although adjuvant therapies (hormone-, chemo-, and radiation therapy) may decrease local recurrence rates, IBTR is still higher after BCS than total mastectomy, and the extent of a "safe margin" is still a debated issue as well as the cost/effectiveness ratio of re-operation (11-13). Actually, although re-excision of positive margins is usually recommended, histological assessment of re-excision samples often reveals no residual disease (RD) in approximately $30 \%$ to $70 \%$ of patients. On the other side, re-excision may have a negative impact on cosmetic outcome and the patient's satisfaction index. Moreover, additional costs and morbidity may be related to re-do surgery and anesthesia, increased post-operative wound complications, and an inherent risk of definitive mastectomy (14-19). According to the European Society of Breast Cancer Specialists (EUSOMA), the target rate of breast cancer patients receiving second-surgery for a primary tumor should be less than $10 \%$ (20).

The aim of our study was to analyze the process of surgical excision and subsequent pathologic examination of the operative specimen in patients undergoing BCS. Primarily, the clinico-pathological features of patients undergoing margin enlargement were analyzed in order to identify a subset of patients who would not have benefited from re-operation; secondly, a standardized protocol of specimen orientation was adopted in order to optimize both the widening procedure and the histopathological examination as well as the oncologic outcome.

\section{Patients and Methods}

A retrospective analysis of an institutional database including 9,060 breast cancer patients with invasive breast cancer undergoing BCS between January 2001 and December 2020 at the Breast Surgery Clinic of San Martino Policlinic Hospital in Genoa (Italy) was performed. Preoperative parameters included: mammographic pattern (i.e., nodule/mass, architectural distortion, microcalcifications); tumor size, and BI-RADS score according to the American College of Radiology and Breast Sonography $(21,22)$. According to European Guideline of Quality Assurance in Breast Cancer Screening and Diagnosis (European Commission), peri- and postoperative parameters included: type of margin involvement (positive margin or close, that is $<1 \mathrm{~mm}$ ), number of intraoperative enlargements; histologic and biologic prognostic factors (i.e., primary tumor histotype, hormone receptor status, Ki67 proliferation rate, and c-erb-2 mutation) $(23,24)$.
The operative sample was always marked by means of clips at the cardinal points in order to address any further re-excision: one clip was positioned at hour 12; two clips at hour 3; three clips at hour 6, and four clips at hour 9. Moreover, one clip was always left at the cardinal points of the tumor bed before wound closure. Hence, the operative sample underwent intraoperative macroscopic assessment by the pathologist in order to assess whether the resection margins were tumor-free. Each patient preoperatively signed an informed consent regarding both treatment-related information and the scientific purposes of the study.

Statistical analysis. Categorical and continuous variables were compared using the chi-square test or Wilcoxon rank-sum test, where appropriate. In order to estimate the probability of RD after intraoperative (one-stage widening of excision margins) or definitive histology (two-stage widening of excision margins), a univariate logistic regression was used to identify potential confounding factors. The explored potential confounding factors were: excision margins, mammographic pattern, mammographic and ecographic BI-RADS classification, tumor histology, tumor diameter, nodal involvement, tumor grading, hormone receptor status, Ki67 expression, HER2-status, age, year of surgery, and surgeon. In the multivariate logistic model, all significant factors at a conservative $20 \%$ level in univariate analysis were included. A backward step-by-step manual selection procedure was used in the multivariate logistic model; an odds ratio $(\mathrm{OR})>1$ indicates a higher risk of positive tumor enlargement.

In order to find patients who could be spared from an intraoperative widening procedure, a predictive score was developed using all clinically (OR value $\leq 0.75$ or $\geq 1.33$ ) and statistically ( $p$ $\leq 0.01)$ significant variables associated with positive tumor enlargement in the multivariate model. Coefficients estimates were normalized by dividing them by the smallest one and rounding the resulting ratios to the nearest integer value.

In the two-stage excision procedure the risk of relapse was also explored. The median follow-up time was calculated using the reverse Kaplan-Meier method. Cox model was used to compute unadjusted and adjusted hazard ratios for recurrence. Potential confounding factors were explored using a univariate Cox model. All potential confounding factors explored in the logistic model were tested also in the univariate Cox model. Moreover, other potential post-operative confounders such as adjuvant chemotherapy, adjuvant radiotherapy, and adjuvant hormonotherapy were explored. All significant factors at a conservative $20 \%$ level in univariate analysis were included in the adjusted Cox model. A hazard ratio $>1$ indicates a higher risk of relapse. All tests were 2-sided and a $p$-value less than 0.05 was considered significant. Statistical analyses were performed by means of SAS System version 9.4.

\section{Results}

Intraoperative widening of the excision margins. An intraoperative widening of the excision margins was requested in 183 patients based on macroscopic pathologic assessment, and two groups of patients were distinguished: tumor positive margins of excision (Group 1: $n=106$ ) or close ( $<1 \mathrm{~mm}$ ) tumor margin (Group 2: $\mathrm{n}=77$ ). Baseline characteristic of patients included in the intraoperative widening of the excision margins groups are reported in Table 
Table I. Clinicopathological features of 183 patients undergoing intraoperative widening procedure.

\begin{tabular}{|c|c|c|}
\hline & $\mathrm{N}^{\circ}$ & $\%$ \\
\hline \multicolumn{3}{|l|}{ Mammographic pattern } \\
\hline Nodule & 151 & 82.5 \\
\hline Breast architectural distortions & 20 & 10.9 \\
\hline Microcalcifications & 12 & 6.6 \\
\hline \multicolumn{3}{|l|}{ Multifocal pattern } \\
\hline Yes & 11 & 6.1 \\
\hline No & 172 & 93.9 \\
\hline \multicolumn{3}{|l|}{ Mammography } \\
\hline BI RADS 3 & 8 & 4.4 \\
\hline BI RADS 4 & 79 & 43.1 \\
\hline BI RADS 5 & 93 & 50.8 \\
\hline BI RADS 6 & 3 & 1.7 \\
\hline Mean tumor diameter (mm) & $16.2 \mathrm{~mm}$ & \\
\hline \multicolumn{3}{|l|}{ ER } \\
\hline Positive (>10\%) & 144 & 78.7 \\
\hline Negative $(<10 \%)$ & 39 & 21.3 \\
\hline \multicolumn{3}{|l|}{ Pgr } \\
\hline Positive (>10\%) & 141 & 77.0 \\
\hline Negative $(<10 \%)$ & 42 & 33.0 \\
\hline \multicolumn{3}{|l|}{ Grading } \\
\hline G1 & 12 & 6.5 \\
\hline G2 & 134 & 73.2 \\
\hline G3 & 37 & 20.3 \\
\hline \multicolumn{3}{|l|}{ Ki67 } \\
\hline$<14 \%$ & 75 & 41.0 \\
\hline$>14 \%$ & 108 & 59.0 \\
\hline \multicolumn{3}{|l|}{ HER2 } \\
\hline Positive & 38 & 20.8 \\
\hline Negative & 145 & 79.2 \\
\hline \multicolumn{3}{|l|}{ Histotype } \\
\hline Invasive ductal carcinoma & 156 & 85.2 \\
\hline Invasive lobular carcinoma & 27 & 14.8 \\
\hline \multicolumn{3}{|l|}{ T Stage } \\
\hline $\mathrm{T} 1 \mathrm{a}$ & 7 & 3.9 \\
\hline $\mathrm{T} 1 \mathrm{~b}$ & 50 & 27.3 \\
\hline $\mathrm{T} 1 \mathrm{c}$ & 80 & 43.7 \\
\hline $\mathrm{T} 2$ & 40 & 21.8 \\
\hline $\mathrm{T} 3$ & 6 & 3.3 \\
\hline \multicolumn{3}{|l|}{ N Stage } \\
\hline No & 135 & 73.8 \\
\hline N1 & 41 & 22.4 \\
\hline N2-N3 & 7 & 3.8 \\
\hline
\end{tabular}

$\mathrm{N}^{\circ}$ : Number; BI-RADS: Breast Imaging Reporting and Data System by the American College of Radiology; ER: estrogen receptor; PgR: progesterone receptor; G: grading: HER2: c-erbB-2 receptor.

I. Briefly, as compared to patients with close tumor margins, patients with positive tumor margins of excision were younger and had more aggressive tumors (i.e., more patients with hormone receptor negative, grade 3, high Ki67, HER2 positive tumors, and more frequent nodal involvement). At definitive histology of the intraoperative margin excision, 57 out of 106 patients (53.8\%) of Group 1 had RD, whereas tumor-free enlargement was always detected in Group 2.
In the univariate model, excision margin status, tumor stage, nodal status, tumor grade, hormone receptors status, Ki67, HER2-status, and age were significantly related to the occurrence of RD after the widening procedure (Table II). In the multivariate model, the strongest association with the presence of RD was found to be related to positive tumor margins (adjusted OR 76.77, 95\% CI=4.51- NE (not estimate), $p=0.003)$. However, other tumor biological features such as hormone receptor status, Ki67, and HER2status were related to RD with higher risk for patients with hormone receptor negative, HER2-positive, and high Ki67 tumors (Table III). All these variables were used to develop a predictive score ranging from 0 to 9 , with higher scores indicating lower risk of RD after the widening procedure. The contribution of each prognostic factor to the calculation of the prognostic score was as follows: close margins, 3 points; hormone receptor positive disease, 2 points; low Ki67, 2 points; HER2 negativity, 1 point; the optimal cutpoint was found to be 3 . In 102 patients with a score $>3$ only 2 patients $(2.0 \%)$ had RD into the operative specimen of the enlargement procedure, whereas in 81 patients with a score $\leq 3,55$ patients $(67.9 \%)$ had $\mathrm{RD}(p<0.001)$.

Two-stage widening of the excision margins. One hundred patients underwent margin enlargement due to detection of tumor-positive margins at definitive histology: in 58 patients the enlargement was performed considering previous clip positioning (clip-guided excision) based on the assumption that these clips, which had been put at the cardinal points of the tumor bed, might more properly address the re-excision procedure; the remaining 42 patients did not undergo any clip-oriented excision and had tumor cavity shave.

At pathologic examination, the mean weight of the operative specimen in the former group of patients was lower (2.4 versus 5.1 grams). Moreover, in 50 out of 58 patients (86.2\%) undergoing clip-oriented excision, RD was found in the operative specimen, whereas the remaining 8 patients $(13.8 \%)$ had a tumor-free excision. Conversely, only 11 out of 42 patients (26.2\%) who did not have a clip-oriented excision had RD in the operative specimen, whereas the remaining 31 patients $(73.8 \%)$ were tumor-free. In the multivariate model, the only factor associated with RD after the widening procedure was the type of surgery, with a higher detection rate of $\mathrm{RD}$ for the clip-oriented excision (adjusted $\mathrm{OR}=16.63,95 \% \mathrm{CI}=5.91-46.74, p<0.0001$ ).

At a median follow-up of 66.7 months $(95 \% \mathrm{CI}=59.3-71.6)$, 19 recurrences occurred: 8 recurrences were observed in 58 $(13.8 \%)$ patients who underwent clip-oriented excision, whereas 11 recurrences were observed in 42 (26.2\%) patients who did not undergo clip-oriented excision. In the multivariate model, no significant difference in term of recurrence was observed between the two types of surgery (adjusted $\mathrm{HR}=0.63,95 \% \mathrm{CI}=0.23-1.72, p=0.36)$. No interaction was 
Table II. Univariate logistic regression model of residual tumor according to explored covariates in patients undergoing intraoperative pathological assessment.

\begin{tabular}{|c|c|c|c|c|}
\hline Covariates & No. of patients & Positive enlargement (\%) & OR $(95 \% \mathrm{CI})$ & $p$-Value \\
\hline Margins & & & & $<0.001$ \\
\hline Close $(<1 \mathrm{~mm})$ & 77 & $0(0)$ & 1 [ref] & \\
\hline Positive & 106 & $57(53.8)$ & $180.02(10.68-\mathrm{NE})$ & \\
\hline Tumor presentation & & & & 0.519 \\
\hline Nodule & 151 & $48(31.8)$ & 1 [ref] & \\
\hline Distortion & 19 & $4(21.0)$ & $0.57(0.18-1.82)$ & \\
\hline Microcalcification & 13 & $5(38.5)$ & $1.34(0.42-4.31)$ & \\
\hline Mammographic results & & & & 0.924 \\
\hline BIRADS 3 & 8 & $3(37.5)$ & $1.34(0.30-5.97)$ & \\
\hline BIRADS 4 & 78 & $24(30.8)$ & $0.99(0.52-1.89)$ & \\
\hline BIRADS 5 & 97 & $30(30.9)$ & 1 [ref] & \\
\hline Ecographic results & & & & 0.785 \\
\hline BIRADS 3 & 7 & $3(42.9)$ & $1.64(0.35-7.80)$ & \\
\hline BIRADS 4 & 77 & $23(29.9)$ & $0.93(0.49-1.78)$ & \\
\hline BIRADS 5 & 99 & $31(31.3)$ & $1[\mathrm{ref}]$ & \\
\hline Tumor histology & & & & 0.772 \\
\hline Ductal carcinoma & 156 & $47(30.1)$ & 1 [ref] & \\
\hline Lobular carcinoma & 27 & $10(37.0)$ & $1.41(0.57-3.47)$ & \\
\hline Tumor stage & & & & 0.047 \\
\hline T1a-b & 66 & $14(21.2)$ & 1 [ref] & \\
\hline $\mathrm{T} 1 \mathrm{c}$ & 78 & $26(33.3)$ & $1.86(0.87-3.95)$ & \\
\hline $\mathrm{T} 2-3$ & 39 & $17(43.6)$ & $2.87(1.21-6.82)$ & \\
\hline Nodal status & & & & 0.090 \\
\hline Negative & 137 & $38(27.7)$ & 1 [ref] & \\
\hline Positive & 46 & $19(41.3)$ & $1.83(0.91-3.68)$ & \\
\hline Grading & & & & $<0.001$ \\
\hline G1 & 12 & $0(0)$ & 1 [ref] & \\
\hline G2 & 132 & $30(22.7)$ & $7.45(0.38-145.38)$ & \\
\hline G3 & 39 & $27(69.2)$ & $55.06(2.69-\mathrm{NE})$ & \\
\hline Receptor status & & & & $<0.001$ \\
\hline Positive & 144 & $23(16.0)$ & 1 [ref] & \\
\hline Negative & 39 & $34(87.2)$ & $35.77(12.65-101.13)$ & \\
\hline Ki67 Status & & & & $<0.001$ \\
\hline Low & 75 & $2(2.7)$ & $1[\mathrm{ref}]$ & \\
\hline High & 108 & $55(50.9)$ & $37.87(8.84-162.20)$ & \\
\hline HER2 status & & & & $<0.001$ \\
\hline Negative & 145 & $33(22.8)$ & 1 [ref] & \\
\hline Positive & 38 & $24(63.2)$ & $5.82(2.71-12.5)$ & \\
\hline Age & & & & 0.029 \\
\hline $1^{\text {st }}$ group & 62 & 27 (42.9) & 1 [ref] & \\
\hline $2^{\text {nd }}$ group & 57 & $17(29.8)$ & $0.57(0.27-1.21)$ & \\
\hline $3^{\text {rd }}$ group & 63 & $13(20.6)$ & $0.35(0.16-0.76)$ & \\
\hline Year of surgery & & & & 0.322 \\
\hline $1^{\text {st }}$ group & 69 & $26(37.7)$ & 1 [ref] & \\
\hline $2^{\text {nd }}$ group & 49 & $14(28.6)$ & $0.66(0.30-1.45)$ & \\
\hline $3^{\text {rd }}$ group & 65 & $17(26.1)$ & $0.59(0.28-1.22)$ & \\
\hline Surgeon & & & & 0.819 \\
\hline 1 & 60 & 19 (31.6) & 1 [ref] & \\
\hline 2 & 43 & $13(30.2)$ & $0.87(0.25-1.82)$ & \\
\hline 3 & 30 & $9(30.0)$ & $0.86(0.32-3.08)$ & \\
\hline 4 & 11 & $4(36.3)$ & $1.16(0.26-4.26)$ & \\
\hline 5 & 15 & $5(33.3)$ & $1.07(0.18-2.52)$ & \\
\hline 6 & 24 & $7(29.1)$ & $0.83(0.15-1.59)$ & \\
\hline
\end{tabular}

OR: Odds ratio; BI-RADS: Breast Imaging Reporting and Data System by the American College of Radiology; G: grading; HER2: c-erbB-2 receptor.

found between type of surgery and RD in the widening procedure, with a HR for recurrence of $0.23(95 \% \mathrm{CI}=0.01$ -
4.63) for patients without RD and a HR of 0.73 (95\%CI=0.163.24 ) for patients with RD ( $p$ for interaction $=0.10$ ). 
Table III. Multivariate logistic regression model.

\begin{tabular}{lcr}
\hline & OR $(95 \% \mathrm{CI})$ & $p$-Value \\
\hline $\begin{array}{l}\text { Margins } \\
\text { Close }\end{array}$ & $1[\mathrm{ref}]$ & 0.003 \\
$\quad$ Positive & $76.77(4.51-\mathrm{NE})$ & \\
Receptor status & $1[\mathrm{ref}]$ & $<0.001$ \\
$\quad$ Positive & $12.91(3.53-47.24)$ & \\
$\quad$ Negative & $1[\mathrm{ref}]$ & 0.001 \\
Ki67 Status & $14.29(2.85-71.53)$ & \\
$\quad$ Low & $1[\mathrm{ref}]$ & 0.036 \\
High & $3.60(1.09-11.90)$ & \\
HER2 status & Negative & \\
Positive &
\end{tabular}

OR: Odds ratio; HER2: c-erbB-2 receptor.

\section{Discussion}

BCS requires several strategies to achieve a low rate of positive margins; first of all, adequate preoperative tumor localisation is crucial. Available techniques include wireguided localisation, charcoal-marking, and radio-guided detection. Moreover, the adoption of a standardized topographic specimen orientation should be pursued in order to obtain correct margin enlargement whenever required, thus reducing both the rate of false-negative margin excision as well as the extent of tissue removal (2). At our Institution, non-palpable tumours are preoperatively marked by means of peri-tumoral sterile charcoal injection.

Regarding intra-operative techniques of tumor margin assessment, macroscopic assessment, frozen section, tactile manipulation, intraoperative ultrasound, touch imprint cytology, and radiographic assessment of specimens have been reported. These techniques can be used alone or in combination to improve the accuracy of perioperative clinical decisionmaking $(21,25,26)$. Although these procedures may prolong operative time, this disadvantage can be easily counterbalanced by a lower re-operation rate, reduction in waiting lists, healthcare costs, as well as less psychological involvement of patients due to re-operation with the inherent feeling of a previous incomplete resection. The pathologist requires an accurate specimen orientation (by means of clips or suture marking) in order to accomplish a reliable pathological assessment as well as to establish the actual location of the positive margin (27-30). We have adopted a standard clipping protocol in order to ease both the pathologist's assessment as well as the re-excision procedure, whenever necessary.

However, although re-excision of positive margins is recommended, histological assessment of re-excision samples often reveals no RD in $30 \%$ to $70 \%$ of patients (1419). In this view, it would be certainly interesting to have a predictive score based on clinical and pathological features of the primary tumor in order to properly select patients with positive/close margins with a high risk of $\mathrm{RD}$ at revision surgery. Cellini et al. (31) identified two risk factors of RD at re-excision, that is: tumor $\geq 2 \mathrm{~cm}$, and high tumor grade. Gurdal et al. (32) suggested that patients with node positive or multifocal cancers had an increased rate of RD at reexcision. Atalay and Irkkan (33) identified at multivariate analysis HER2 positivity and tumor to specimen volume ratio $>70 \%$ as independent predictors of RD at re-excision surgery. Mimouni et al. (12) proposed a predictive model based on a 7-point score including different factors: a cumulative length of all positive margins $>5 \mathrm{~mm}$; invasion by ductal carcinoma in situ only; a pathological tumor $>30$ $\mathrm{mm}$; and a pathological tumor size $<30 \mathrm{~mm}$ with a discrepancy of $>50 \%$ between pathological and radiological tumor size. Although three risk categories were identified in the evaluation set of patients (low, moderate, and high risk, with RD in $16 \%, 65 \%$, and $100 \%$ of re-excision specimens, respectively), at the following validation assessment, up to $25 \%$ in the low-risk category had RD at revision surgery, a too high rate to omit re-excision in this subset of patients.

In our present experience, a multiparametric predictive model was developed with a higher risk of RD in patients with positive excision margins, hormone receptor negative, HER2-positive and high Ki67 tumors; the cut-off limit $\leq 3$ allowed to detect patients with a significantly higher risk of RD in the widening procedure $(p<0.001)$. We could not validate this model in the set of patients who underwent margin enlargement due to positive margins at definitive histology because they were a rather heterogeneous group of patients as for the type of surgery ("clip-oriented" and "no clip-oriented"); however, this issue will certainly require a prospective validation in another set of patients undergoing a widening procedure in order to check its predictivity as well as clinical relevance.

As regards to surgical details, cavity shave has been proposed at initial surgery to reduce the rate of positive/close margins; however, recent clinical experiences suggest that although it may actually reduce the rate of positive margins as compared to the no-shave group, the "shave" group experienced longer operative time (median $76 \mathrm{vs} .66 \mathrm{~min}$, $p<0.01)$ coupled with a lower re-excision rate for positive margins $(10.9 \%$ vs. $27.6 \%, p<0.01)$ but no significant difference in overall costs both from the payer or the hospital perspective in the subsequent 90 days (34-36). Furthermore, any unnecessary enlargement of the procedure may hamper the final cosmetic outcome or even require a mastectomy whenever there is a critical ratio between excisional and residual breast volume. For this reason, a targeted excision is certainly welcome to reduce the extent of breast resection.

In the present experience, this was accomplished by clipping according to a standardized protocol both the operative sample (one clip was positioned at hour 12; two 
clips at hour 3; three clips at hour 6, and four clips at hour 9) as well as the tumor bed. This targeted approach allowed to reduce not only the weight of the re-excision specimen but, mostly, it achieved a higher rate of RD (adjusted $\mathrm{OR}=16.63,95 \% \mathrm{CI}=5.91-46.74, p<0.0001)$. The lower rate of RD after simple cavity shaving might imply a higher falsenegative rate, which could be translated into an increased recurrence rate. However, due to the rather low rate of recurrence detected in our clinical experience (overall, 19 recurrences) there was not enough power to demonstrate whether a clip-oriented widening procedure might be statistically related to a reduce risk of IBTR.

\section{Conclusion}

The correct identification of excision margins after BCS requires a close collaboration between the radiologist, the surgeon, and the pathologist; the standardization of marking, excision, orientation, and sample assessment are essential in order to reduce useless re-operation and minimize the extent of glandular excision, thus improving cosmetic outcome and, possibly, reduce the recurrence rate due to RD. A prospective validation of our predictive model in a subsequent sample of patients undergoing a widening procedure might better define its predictivity and clinical relevance.

\section{Conflicts of Interest}

This study received no grant and all Authors declare that they have no conflicts of interest in relation to this study.

\section{Authors' Contributions}

Piero Fregatti, Marco Gipponi: Study Planning, Surgical Treatment, Manuscript editing; Giulia Atzori, Raffaele De Rosa, Raquel Diaz, Chiara Cornacchia, Marco Sparavigna: follow-up and data management; Alessandro Garlaschi, Alessandra Fozza, Liliana Belgioia: radiologic assessment and data management; Francesca Pitto: pathological evaluation; Luca Boni, Eva Blondeaux: statistical analysis; Francesca Depaoli, Federica Murelli, Simonetta Franchelli: surgical treatment and follow-up; Gabriele Zoppoli, Matteo Lambertini: medical treatment and data management; Daniele Friedman: study planning, surgical treatment, manuscript review.

\section{References}

1 Gradishar WJ, Anderson BO, Abraham J, Aft R, Agnese D, Allison KH, Blair SL, Burstein HJ, Dang C, Elias AD, Giordano SH, Goetz MP, Goldstein LJ, Isakoff SJ, Krishnamurthy J, Lyons J, Marcom PK, Matro J, Mayer IA, Moran MS, Mortimer J, O'Regan RM, Patel SA, Pierce LJ, Rugo HS, Sitapati A, Smith KL, Smith ML, Soliman H, Stringer-Reasor EM, Telli ML, Ward JH, Young JS, Burns JL and Kumar R: Breast cancer, version 3.2020, NCCN clinical practice guidelines in oncology. J Natl Compr Canc Netw 18(4): 452-478, 2020. PMID: 32259783. DOI: $10.6004 /$ jncen.2020.0016
2 O'Kelly Priddy CM, Forte VA and Lang JE: The importance of surgical margins in breast cancer. J Surg Oncol 113(3): 256-263, 2016. PMID: 26394558. DOI: 10.1002/jso.24047

3 Brouwer de Koning SG, Vrancken Peeters MTFD, Jóźwiak K, Bhairosing PA and Ruers TJM: Tumor resection margin definitions in breast-conserving surgery: systematic review and meta-analysis of the current literature. Clin Breast Cancer 18(4): e595-e600, 2018. PMID: 29731404. DOI: 10.1016/j.clbc.2018.04.004

4 Dumitru D, Douek M and Benson JR: Novel techniques for intraoperative assessment of margin involvement. Ecancermedicalscience 12: 795, 2018. PMID: 29434661. DOI: 10.3332/ecancer.2018.795

5 Greenup RA, Peppercorn J, Worni M and Hwang ES: Cost implications of the SSO-ASTRO consensus guideline on margins for breast-conserving surgery with whole breast irradiation in stage I and II invasive breast cancer. Ann Surg Oncol 21(5): 1512-1514, 2014. PMID: 24577813. DOI: 10.1245/s10434-014-3605-x

6 Morrow M, Van Zee KJ, Solin LJ, Houssami N, ChavezMacGregor M, Harris JR, Horton J, Hwang S, Johnson PL, Marinovich ML, Schnitt SJ, Wapnir I and Moran MS: Society of Surgical Oncology-American Society for Radiation Oncology-American Society of Clinical Oncology consensus guideline on margins for breast-conserving surgery with wholebreast irradiation in ductal carcinoma in situ. Ann Surg Oncol 23(12): 3801-3810, 2016. PMID: 27527714. DOI: 10.1245/ s10434-016-5449-z

7 Galimberti V, Taffurelli M, Leonardi MC, Aristei C, Trentin C, Cassano E, Pietribiasi F, Corso G, Munzone E, Tondini C, Frigerio A, Cataliotti L and Santini D: Surgical resection margins after breast-conserving surgery: Senonetwork recommendations. Tumori 2016(3): 284-289, 2016. PMID: 27103209. DOI: $10.5301 / \mathrm{tj} .5000500$

8 Pilewskie M and Morrow M: Margins in breast cancer: How much is enough? Cancer 124(7): 1335-1341, 2018. PMID: 29338088. DOI: $10.1002 /$ cncr.31221

9 Kuerer HM, Smith BD, Chavez-MacGregor M, Albarracin C, Barcenas CH, Santiago L, Edgerton ME, Rauch GM, Giordano SH, Sahin A, Krishnamurthy S, Woodward W, Tripathy D, Yang WT and Hunt KK: DCIS margins and breast conservation: MD Anderson Cancer Center multidisciplinary practice guidelines and outcomes. J Cancer 8(14): 2653-2662, 2017. PMID: 28928852. DOI: $10.7150 /$ jca.20871

10 Fregatti P, Gipponi M, Depaoli F, Murelli F, Guenzi M, Bonzano E, Ceppi M and Friedman D: No ink on ductal carcinoma in situ: a single centre experience. Anticancer Res 39(1): 459-466, 2019. PMID: 30591495. DOI: 10.21873/anticanres.13134

11 Early Breast Cancer Trialists' Collaborative Group (EBCTCG): Effects of chemotherapy and hormonal therapy for early breast cancer on recurrence and 15-year survival: an overview of the randomised trials. Lancet 365(9472): 1687-1717, 2005. PMID: 15894097. DOI: 10.1016/S0140-6736(05)66544-0

12 Mimouni M, Lecuru F, Rouzier R, Lotersztajn N, Heitz D, Cohen J, Fauconnier A and Huchon C: Reexcision for positive margins in breast cancer: A predictive score of residual disease. Surg Oncol 24(3): 129-135, 2015. PMID: 26298198. DOI: 10.1016/j.suronc.2015.08.003

13 Pilewskie M and Morrow M: Extent and role of margin control for DCIS managed by breast-conserving surgery. In: Newman LA, Bensenhaver JM (eds). Ductal carcinoma in situ and 
microinvasive/borderline breast cancer. New York, Springer, pp 67-83, 2015.

14 Rubio IT, Ahmed M, Kovacs T and Marco V: Margins in breast conserving surgery: A practice-changing process. Eur J Surg Oncol 42(5): 631-640, 2016. PMID: 26880017. DOI: $10.1016 /$ j.ejso .2016 .01 .019

15 Houvenaeghel G, Lambaudie E, Buttarelli M, Cohen M, Bannier $\mathrm{M}$, Tallet $\mathrm{A}$ and Jacquemier $\mathrm{J}$ : [Margin status in invasive breast cancer]. Bull Cancer 95(12): 1161-1170, 2008. PMID: 19091649. DOI: $10.1684 /$ bdc.2008.0766

16 Boughey JC, Hieken TJ, Jakub JW, Degnim AC, Grant CS, Farley DR, Thomsen KM, Osborn JB, Keeney GL and Habermann EB: Impact of analysis of frozen-section margin on reoperation rates in women undergoing lumpectomy for breast cancer: evaluation of the National Surgical Quality Improvement Program data. Surgery 156(1): 190-197, 2014. PMID: 24929768. DOI: $10.1016 /$ j.surg.2014.03.025

17 King TA, Sakr R, Patil S, Gurevich I, Stempel M, Sampson M and Morrow M: Clinical management factors contribute to the decision for contralateral prophylactic mastectomy. J Clin Oncol 29(16): 2158-2164, 2011. PMID: 21464413. DOI: 10.1200/JCO. 2010.29.4041

18 Olsen MA, Nickel KB, Margenthaler JA, Wallace AE, Mines D, Miller JP, Fraser VJ and Warren DK: Increased risk of surgical site infection among breast-conserving surgery re-excisions. Ann Surg Oncol 22(6): 2003-2009, 2015. PMID: 25358666. DOI: 10.1245/s10434-014-4200-x

19 Reyna C and DeSnyder SM: Intraoperative margin assessment in breast cancer management. Surg Oncol Clin N Am 27(1): 155-165, 2018. PMID: 29132558. DOI: 10.1016/j.soc. 2017.08.006

20 Biganzoli L, Marotti L, Hart CD, Cataliotti L, Cutuli B, Kühn T, Mansel RE, Ponti A, Poortmans P, Regitnig P, van der Hage JA, Wengström Y and Rosselli Del Turco M: Quality indicators in breast cancer care: An update from the EUSOMA working group. Eur J Cancer 86: 59-81, 2017. PMID: 28963914. DOI: 10.1016/j.ejca.2017.08.017

21 Singletary SE: Surgical margins in patients with early-stage breast cancer treated with breast conservation therapy. Am J Surg 184(5): 383-393, 2002. PMID: 12433599. DOI: 10.1016/ s0002-9610(02)01012-7

22 ACR BI-RADS Atlas, 2013. Available at: https://radiology assistant.nl/breast/bi-rads-for-mammography-and-ultrasound2013 [Last accessed on December 14, 2021]

23 Perry N, Broeders M, de Wolf C, Törnberg S, Holland R and von Karsa L: European guidelines for quality assurance in breast cancer screening and diagnosis. Fourth edition-summary document. Ann Oncol 19(4): 614-622, 2008. PMID: 18024988. DOI: $10.1093 /$ annonc/mdm481

24 Gipponi M, Fregatti P, Garlaschi A, Calabrese M, Baccini P, Gallo M, Murelli F, Margarino C, Bobbio C and Friedman D: Clinical decision-making in atypical and suspicious categories in fine-needle aspiration cytology of the breast. Anticancer Res 35(4): 2369-2374, 2015. PMID: 25862902.

25 Trippel M, Slotta-Huspenina J, Becker K, Rau T, Paepke S, Maurer-Marti F and Langer R: Macroscopic evaluation of the trimmed frozen block is a helpful tool for intraoperative assessment of resection margins of breast cancer specimens. Int J Surg Pathol 26(8): 693-700, 2018. PMID: 29953301. DOI: $10.1177 / 1066896918780346$
26 Schiaffino S, Massone E, Gristina L, Fregatti P, Rescinito G, Villa A, Friedman D and Calabrese M: Vacuum assisted breast biopsy (VAB) excision of subcentimeter microcalcifications as an alternative to open biopsy for atypical ductal hyperplasia. $\mathrm{Br}$ J Radiol 91(1085): 20180003, 2018. PMID: 29451396. DOI: 10.1259/bjr.20180003

27 Altman AM, Nguyen DD, Johnson B, Marmor S, Klein ME, Tuttle TM and Hui JYC: Intraoperative inking is superior to suture marking for specimen orientation in breast cancer. Breast J 26(4): 661-667, 2020. PMID: 31482614. DOI: 10.1111/tbj.13508

28 Volleamere AJ and Kirwan CC: National survey of breast cancer specimen orientation marking systems. Eur J Surg Oncol 39(3): 255-259, 2013. PMID: 23287819. DOI: 10.1016/j.ejso.2012.12.008

29 Molina MA, Snell S, Franceschi D, Jorda M, Gomez C, Moffat FL, Powell J and Avisar E: Breast specimen orientation. Ann Surg Oncol 16(2): 285-288, 2009. PMID: 19050966. DOI: 10.1245/s 10434-008-0245-z

30 Patel $\mathrm{J}$ and Jenkins S: A technique for marking oncological breast tissue specimens. Ann Med Surg (Lond) 7: 7-8, 2016. PMID: 27158488. DOI: 10.1016/j.amsu.2016.02.012

31 Cellini C, Hollenbeck ST, Christos P, Martins D, Carson J, Kemper S, Lavigne E, Chan E and Simmons R: Factors associated with residual breast cancer after re-excision for close or positive margins. Ann Surg Oncol 11(10): 915-920, 2004. PMID: 15383425. DOI: 10.1245/ASO.2004.12.037

32 Gurdal SO, Karanlik H, Cabioglu N, Ozcinar B, Yavuz E, Tuzlali S and Ozmen V: Positive or close margins in breast conserving surgery: is re-excision always necessary? Eur J Surg Oncol 38(5): 399-406, 2012. PMID: 22440741. DOI: 10.1016/ j.ejso.2012.02.182

33 Atalay $\mathrm{C}$ and Irkkan C: Predictive factors for residual disease in re-excision specimens after breast-conserving surgery. Breast $\mathrm{J}$ 18(4): 339-344, 2012. PMID: 22616572. DOI: 10.1111/j.15244741.2012.01249.x

34 Mimouni M, Lecuru F, Rouzier R, Lotersztajn N, Heitz D, Cohen J, Fauconnier A and Huchon C: Reexcision for positive margins in breast cancer: A predictive score of residual disease. Surg Oncol 24(3): 129-135, 2015. PMID: 26298198. DOI: 10.1016/j.suronc.2015.08.003

35 Chagpar AB, Killelea BK, Tsangaris TN, Butler M, Stavris K, Li F, Yao X, Bossuyt V, Harigopal M, Lannin DR, Pusztai L and Horowitz NR: A randomized, controlled trial of cavity shave margins in breast cancer. N Engl J Med 373(6): 503-510, 2015. PMID: 26028131. DOI: 10.1056/NEJMoa1504473

36 Chagpar AB, Horowitz NR, Killelea BK, Tsangaris T, Longley P, Grizzle S, Loftus M, Li F, Butler M, Stavris K, Yao X, Harigopal M, Bossuyt V, Lannin DR, Pusztai L, Davidoff AJ and Gross CP: economic impact of routine cavity margins versus standard partial mastectomy in breast cancer patients: results of a randomized controlled trial. Ann Surg 265(1): 39-44, 2017. PMID: 27192352. DOI: 10.1097/SLA.0000000000001799

37 Dumitru D, Douek M and Benson JR: Novel techniques for intraoperative assessment of margin involvement. Ecancermedicalscience 12: 795, 2018. PMID: 29434661. DOI: 10.3332/ecancer.2018.795

Received November 26, 2021

Revised December 14, 2021

Accepted December 15, 2021 